\title{
What are the Challenges of Building a Smart City?
} Haven Allahar

\author{
" Smart city development requires not only technological enablers \\ but also a new way of thinking among cities, businesses, citizens \\ and academia which includes key development stakeholders. " \\ Heikki Ruohomaa, Vesa Salminen, Iivari Kunttu \\ 'Smart City' Researchers
}

\begin{abstract}
The recent emergence of the concept of 'smart cities' presents challenges to city administrators for planning, managing, and governing modern cities in the digital age. Research on smart cities has tended to focus on the attributes of cities at a more developed stage. Instead, this article departs from that trend by discussing an aspiring smart city in a small-island developing country. The purpose of the study is to examine the steps required for building a smart city against a background of the concept of smart cities, taken in the context of an empirical study of an aspiring small smart city. The main finding is that there is no single route to becoming a smart city, but rather there are critical steps that can be adopted as part of a building process for achieving that objective. This work adds value in presenting a way to synthesize the smart city concept with empirical work involving one small smart city's aspirations and achievements. The article fills a partial gap in the smart city literature and has implications for aspiring city administrators, smart city builders, persons concerned with the application of ICT to address city challenges, as well as for students of urban planning, development, and management.
\end{abstract}

\section{Introduction}

The concept of a 'smart city' emerged from studies in urbanism, combined with information and communications technologies (ICTs). It now extends to include interactions with and between governmental organizations, involving broader society, and the use of technology through technology-enablers such as the Internet, and early onset of 'artificial intelligence' (Ruohomaa et al., 2019). The term 'smart city' became popular around 2009, arising from several descriptive adjectives being used about cities, such as: virtual, digital, wired, intelligent, information, knowledge, creative, green, and clever (Kola-Bezka et al., 2016; Thompson, 2016; Veselitskaya et al., 2019; Min et al., 2019). In the course of this linguistic history, many definitions and classifications have been proposed, yet there is still no agreed upon definition of what constitutes a 'smart city'. Instead, multiple definitions are now available based on varying perspectives (Meijer \& Bolivar, 2016; Serrano, 2018; Schipper \& Silvius, 2018).

One appealing recent perspective proposed by Min et al. (2019), is to view the term 'smart city' as an umbrella concept, due to the absence of a consensus. This is largely because the concept is still emerging among scholars, and also since cities are or can be such diverse entities, each with unique attributes and challenges. Nevertheless, both residents and city administrators of many cities around the world at the current time claim to be 'smart', or aspire to achieve the status of being a 'smart city' (Thompson, 2016).

This article suggests a definition adapted by the author from the Inter-American Development Bank (IDB) together with a listing of various definitions compiled by Schipper and Silvius (2018), as follows: 


\section{What are the Challenges of Building a Smart City?}

\section{Haven Allahar}

\begin{abstract}
"A smart city places people at the center of development, invests in human and social capital, manages resources wisely, incorporates ICT into urban management, emphasizes collaborative planning and citizen participation. The aim of a smart city is geared towards promoting sustainable development and improvement in the quality of life of its citizens through ongoing initiatives that support innovation, competitiveness, attractiveness, and resilience of the city".
\end{abstract}

Due to the fact that that studies of the development and operation of smart cities are still in their infancy, there are many gaps in the literature. These include small cities in developing countries being given less attention (Ruohomaa et al., 2019), inconsistencies in approaches because each city is deemed to be unique with no development template for how cities change over time and develop (Coletta et al., 2019), and deficient outcomes for studies trying to formulate a clear development pathway. Because of the ambiguity surrounding the term 'smart city' (Min et al., 2019), some scholars asserted that there are no 'flagship' examples of smart cities, but rather merely cities pursuing the 'smart' label (Snow et al., 2016). That said another look at the landscape anticipates 88 smart cities globally by 2025 (Glasmeier \& Nebiolo, 2016). Smart city development has become associated with many initiatives, including urban living labs (31\%), smart government (22\%), smart environment (16\%), and open data (13\%) (Thompson, 2016).

One problem is whether a set of clear steps to developing a smart city can be identified in the context of the newness and fragmented condition of the concept. This paper adds proposed development actions for addressing the problem, which are outlined in (Table 1) as a suggested smart city development path. The purpose of this paper is to provide insights into the emergent phenomenon of smart cities and to trace the steps required for building a smart city, despite the complex and fragmented context. This article documents the findings of a case with a city located in a small island developing state, which is openly aspiring to be 'smart'. The research findings note the challenges and flaws of this novel initiative. The case involves the city of Port of Spain, the capital of Trinidad and Tobago, as an example of a single smart city case. their provides the rare scenario of a small developing island, and the only city in the Caribbean-island region that has embarked on the path of developing a 'smart city' (Yin, 2003; Siggelkow, 2007; Dasgupta, 2015). This Singapore is the most advanced small-island city where the 'becoming smart' approach was to emphasize transport, home and environment, business productivity, health and enabled ageing, and public-sector services, along with testing the application of smart technologies (Ho, 2017).

No accepted theory can be said to currently govern the design and operations of smart cities (Harrison \& Donnelly, 2011). This article is therefore underpinned by theories about urban systems and the feature of stakeholder collaboration. Harrison and Donnelly (2011) viewed urban systems theory as comprising arbitrarily arranged layers of the natural environment, infrastructure, resources, services, and social systems. The authors argued that a theoretical foundation for smart city interventions was needed to provide links for the thinking of architects, planners, developers, city managers, and other city stakeholders.

Stakeholder participation in cities has generally been viewed within a triple-helix system of collaboration among universities/tertiary institutes, industry/business, and governmental authorities (Etzkowitz \& Leydesdorff, 2000; Thompson, 2016). Such collaboration was then extended to a quadruple-helix, by including the media, creative industries, and culture as participants (van Waart, Mulder \& de Bont, 2016); and next to a quintuple helix by adding the natural environment (Carayannis et al., 2012; McAdam \& Debackere, 2018). The success of building smart cities has been traced by some scholars to depth of community engagement and level of citizen participation (Snow et al., 2016; Einola et al., 2019).

The rest of the paper presents an overview of the concept of 'smart cities' to add clarity to the concept's vagueness and promote greater understanding. It then introduces the challenge of developing a smart city as the central problem of the article. It turns next to discuss the case of Port of Spain as an island-based city aspiring to be 'smart', along with a critical analysis of its progress. After that, it highlights the findings related to both constraints and potential benefits of developing a smart city, and outlines the main conclusions from the article's insights.

\section{Overview of the Concept of Smart Cities}

\section{Clarifying the Concept}

Early research on smart cities focused on the application of ICTs to city operations, as well as the provision of 


\section{What are the Challenges of Building a Smart City?}

\section{Haven Allahar}

services. Current research now focuses on the impacts of specific projects and initiatives that utilize technologies such as big data analytics (Bibri \& Krogstie, 2017). A clear gap, however, has emerged regarding the role of human capital in the smart city development process. Moreover, specific flaws have been shown due to the lack of "a holistic orientation as to integrating environmental, economic, and social considerations and goals of sustainability with technological opportunities" (Bibri \& Krogstie, 2017).

Recently, the term smart 'sustainable' city was suggested (Schipper \& Silvius, 2018), which has been considered as a questionable addition (Allam \& Newman, 2018), while sustainability was generally de-emphasized in the literature (Bibri \& Krogstie, 2017). Moreover, the concept of 'smart cities' is currently in flux, and the many different labels applied merely highlight particular aspects of what a smart city should contain. This includes emphasis on each city's ICT features, various challenges, and overall uniqueness (Meijer \& Bolivar, 2016; Caragliu \& Del Bo, 2016; Ruohomma et al., 2019). The term 'smarter' city, meant to refer to the growing utilization of advanced ICT, has also emerged as a future concept (Bibri \& Krogstie, 2017). The majority of smart city concepts also emphasize a critical need for wide stakeholder collaboration in planning and implementing initiatives from the outset (Markkula \& Kune, 2015; Jussila et al., 2019).

\section{Role of ICT}

The increasing application of technology to the functioning of cities worldwide is generating a growing body of research work on smart cities. Nevertheless, these studies still remain fragmented (Meijer \& Bolivar, 2016). Smart city concepts are drawn from several fields of knowledge, including ICT, urban studies, egovernment, and public administration (Meijer et al., 2016). This diversity of contributions can sometimes lead to a confused understanding.

However, there is consensus that a city's overall 'smartness' is not measured by investment in expensive technology exclusively, but rather by the extent of improvement in citizens' lives (Thompson, 2016). Such improvement was said to require smart networks for activities such as transportation, water supply, and waste treatment (Hayat, 2016), using networks to integrate technologies, systems, and services, as well as provide capabilities for future development (Min et al., 2019).
The debate on smartness highlights two different approaches to the study of smart cities: the "ICToriented approach and the people-oriented approach" (Bibri \& Krogstie, 2017). Similarly, smart cities were classified by Meijer and Bolivar (2016) as either having a focus on the application of technology to issues such as transportation, energy, and traffic congestion to foster urban development and sustainability; or a focus on human capital and resources as central to the efficient functioning of smart cities. The latter involves a governance focus that stresses stakeholder collaboration with tertiary institutes to create innovation hubs as described by Allahar and Sookram (2019), and a general focus that represents a combination of technology, human resources, and governance. The ICT approach has been criticized as promoting the sale of technological devices driven by IT corporations' profit motive, while being disruptive, expensive, and tending to disadvantage older citizens (Glasmeier \& Nebiolo, 2016; van Waart, 2016; Allam \& Newman, 2018).

\section{Smart City Characteristics}

The early characteristics of smart cities were identified as comprising:

a) smart economy (innovative and entrepreneurial, digital currency)

b) smart people (qualified, pursues life-long learning, creative)

c) smart governance (participatory, provision of public and social services)

d) smart mobility (access to transport, ICT

infrastructure, sustainable and safe transport systems)

e) smart environment (attractiveness of natural

environment, sustainable resource management)

f) smart living (facilities for culture, health, safety, housing, education, and social cohesion) (Giffinger et al., 2007).

The specific characteristics of smart governance, people, and infrastructure were later elaborated by researchers as:

1. smart governance emphasizes the need for a collaborative digital environment through knowledge networks that promote business competitiveness (Pereira et al., 2018)

2. the smart people aspect involves combining social and human capital within the city in a collaborative arrangement where citizens participate in decisionmaking and contribute to necessary changes (Snow et al., 2016; Bibri \& Krogstie, 2017) 


\section{What are the Challenges of Building a Smart City?}

\section{Haven Allahar}

3. smart infrastructure implies the application of ICTs to the challenges of urbanization, and to creating a city for the future (Sánchez-Corcuera et al., 2019).

Smart infrastructure has been identified as needing to go beyond the mere use of ICTs towards solution-finding and enabling greater efficiency through smart devices, big data capture and analysis. A need arises for using big data to exploit knowledge through human capital, that provides interconnectivity for knowledge sharing (Allam \& Newman, 2018; Min et al., 2019).

\section{Challenge of Developing a Smart City}

\section{Attributes and Distinguishing Features}

Very few smart cities have been attempted and are rarely built from scratch. Instead, they are constructed upon existing systems, practices, infrastructure, and organizational structures (Glasmeier \& Nebiolo, 2016; Meier et al., 2016). How can a smart city be distinguished from a traditional city? Generally, the attributes of smart cities include smart infrastructure including:

a) a smart electrical grid

b) smart water management

c) smart traffic and transportation systems

d) smart waste-water management systems that reduce, redeploy, recycle, and segregate waste

e) waste-to-energy compost

f) e-waste management

g) smart security systems

h) e-government with data sharing in real time across a secured network (Hayat, 2016).

In practice, a smart city displays the following features:

1. Shared ICT, common infrastructure for communications using an optical fiber backbone

2. Information collection via sensors like smart meters monitored from a central control center

3. Open government to bridge gaps between citizens and administrations

4. Energy-efficient technologies like smart streetlights

5. Time optimization like multi-level parking for revenue generation, global positioning system-enabled vehicles

6. Zero emissions which means reduced utility bills

7. Green rooftops and a green environment (Hayat, 2016).

\section{Development Path}

At the operational level, smart city development involves multilevel smart city municipal governance, and a socio- technical dynamic that reinforces "human collaboration and technological systems" (Meijer et al., 2016). However, the city of Dublin, Ireland was labeled an "accidental smart city", because it was implementing smart city initiatives without a master plan (Coletta et al., 2019). While a general consensus holds that there is no single route or path to developing a smart city, and that cities are considered diverse and complex, with each city being unique, cities have utilized different approaches to achieving smartness and followed different development paths (Meijer et al., 2016). It has also been argued that "a smart city is far from stable and linear in nature, but unfolds through a set of contingent and relational processes" (Coletta et al., 2019). Colding, Colding and Barthel (2020) similarly lamented the absence of debate on the smart city model because "no one actually knows what type of society the SC model in the end will generate", with high levels of complexity a likely result.

At the implementation level, research has pointed out that copying best practices from other cities was not always the best solution, but rather aligning initiatives with development strategies, human resource policies, ICTs, and configuring the city was required. However, evaluation of progress with smart city initiatives revealed that most cities did not go beyond creating open data portals, providing free $\mathrm{Wi}-\mathrm{Fi}$ and smart phone applications, and that the data collected were rarely put to productive use in supplying new utility services (Sánchez-Corcuera et al., 2019). The insight gained from these authors suggests that smart city developers should first design the architecture and standards to be utilized in the given city to help expedite the implementation process.

\section{Development Steps Applicable to the Case}

According to Glasmeier and Nebiolo (2016), no consensus exists on the steps required for building a smart city. For the purpose of addressing the problem stated in this article, this paper proposes critical steps for developing a smart city that have been identified as relevant for early stage smart cities in the Latin American and Caribbean region detailed below (Bouskela et al., 2016). These steps are presented as a way to create a pathway to developing Port of Spain into a smart city, and address various problems posed in this regard.

\section{Port of Spain - Smart City Planning}

Port of Spain is the capital of Trinidad and Tobago, a small island state located in the Southern Caribbean 


\section{What are the Challenges of Building a Smart City?}

\section{Haven Allahar}

Table 1. Steps for Developing a Smart City

\begin{tabular}{|c|c|}
\hline Building Blocks & Activities \\
\hline Leadership & $\begin{array}{l}\text { Select a leadership team with the requisite technical knowledge and } \\
\text { management skills, and build strong working relationships }\end{array}$ \\
\hline Diagnosis & $\begin{array}{l}\text { Conduct a deep diagnosis of city-specific challenges, including the } \\
\text { technological infrastructure's capability regarding connectivity, } \\
\text { systems, equipment, institutional and human resource capacities; and } \\
\text { secure the involvement of key stakeholders through consultation }\end{array}$ \\
\hline Action plan & $\begin{array}{l}\text { Prepare a smart city action plan based on a cost-benefit analysis } \\
\text { accounting for: technology issues, institutional elements, the } \\
\text { regulatory framework, integrating technology and management } \\
\text { systems, devising collaborative arrangements with key stakeholders, } \\
\text { and sources of funding }\end{array}$ \\
\hline $\begin{array}{l}\text { Implementation } \\
\text { plan }\end{array}$ & $\begin{array}{l}\text { Develop an implementation plan that allows for setting timelines and } \\
\text { targets focused on manageable pilot projects, while confirming } \\
\text { available sources of finance and technology requirements. A project } \\
\text { planning and management approach which includes foresight } \\
\text { planning is recommended (Allahar, 2019) }\end{array}$ \\
\hline Collaboration & $\begin{array}{l}\text { Establish partnership arrangements that target the creation of a smart } \\
\text { ecosystem for fostering startups, retaining talented people, promoting } \\
\text { innovation, and pursuing competitiveness and entrepreneurship in } \\
\text { the city, region, and country }\end{array}$ \\
\hline Evaluation & $\begin{array}{l}\text { Evaluate project results to determine which solutions are meeting } \\
\text { objectives, eliminating errors through monitoring, evaluating, and } \\
\text { providing feedback; and documenting lessons learnt for effecting } \\
\text { public management changes and adjustments. }\end{array}$ \\
\hline
\end{tabular}

with the city aspiring to be smarter. The city is $12.3 \mathrm{~km} 2$ in size with a population of 50,000, and a density of 4,000 per $\mathrm{km} 2$. It is prone to flooding as a coastal city, characterized by informal housing settlements, traffic congestion, vehicle parking issues, and the nonapplication of sustainable indicators for guiding local development (Beard, 2012). The city offers the highest levels of commercial business operations, services, and public administrative functions in the country, and has benefitted, as a port city, from the downstream activities and industries of import and export business (UN Habitat, 2012). Port of Spain celebrated its 106-year anniversary as a city in 2020, based around the theme of "Resilience - a city recovering, a city rebuilding, a city rising" (Fletcher, 2020).

\section{Action Plan and Evaluation}

In collaboration with the IDB, two initiatives were undertaken relating to smart city development. A Sustainable Port of Spain Action Plan focused on the implementation of three groups of initiatives (IDB, 2012), and a case study evaluation of the Port of Spain Emerging and Sustainable Cities initiative (IDB, 2016).

The action plan outlined the initiatives required as:
- Environmental and infrastructure projects including protecting watersheds, upgrading settlements, improving public safety and water supply, rehabilitating drainage, solid waste management, and climate change adaptation

- Cultural and heritage activities, such as preservation of heritage sites and attractions and upgrading and beautifying urban spaces that were established as critical to tourism development in the city

- Social and economic development initiatives involving: empowering communities to execute local development plans; collaborating with local businesses; creating employment; and providing training.

In 2014, Port of Spain was included in the IDBs Emerging Sustainable Cities' initiative. A subsequent case study evaluation of the initiative identified the following trends and characteristics (Table 2) (IDB, 2016).

\section{Critical Analysis of the Port of Spain Experience}

\section{Action Planning}

This paper assesses the progress of Port of Spain towards becoming a smart city against the following markers: the 


\section{What are the Challenges of Building a Smart City?}

\section{Haven Allahar}

Action Plan prepared for the city (IDB, 2012), the case study evaluation of implementing the action plan (IDB, 2016), the suggested critical steps for building a smart city (Bousekela et al., 2016), and the author's insider experience as a development planning consultant for the city. An assessment of the Action Plan revealed a slow progress of achievements, especially in rehabilitating drainage and mitigating the yearly flooding incidents in the city, and likewise in relocating a solid waste facility that is currently located on the city's outskirts. The city is home to the cruise shipping port facility, but efforts at developing and managing the visitor sites and attractions remain slow moving, despite having available a formulated development and management framework(Allahar, 2015). The social and economic development program is a collaborative approach, but implies the need for engaging a formal quintuple helix arrangement (Carayanis et al., 2012) to enable greater involvement of all citizens, institutions, nongovernmental organizations, community-based organizations, and environmental activists with SME development.

\section{Evaluation of Port of Spain}

The sustainable cities case study revealed that many areas in Port of Spain were evaluated as having below minimum sustainability levels. This was emphasized by its vulnerability to flooding, risks of natural disaster, degradation of the urban environment, inadequate management of growth; low standard of urban mobility and safe transport (described as a smart mobility ecosystem by Pulkkinen, Jussila, Partanen, Trotskii, and Laiho, 2019), and poor competitiveness (IDB, 2016).

The city is still in its early stages of working towards becoming smarter, and the critical development steps have not yet been pursued diligently. A significant implication is that there are many deficiencies in the city's development process because of the lack of identifiable leadership. Instead, in Port of Spain, different city and governmental officials assume parttime leadership roles. This creates a problem of both responsibility and accountability, with fewer people in full-time roles available.

Further, the sustainable cities analysis of human and organizational requirements for implementing smart initiatives was not thorough. Port of Spain's 'smart city' plan has been pursued only in a piecemeal fashion, as in the Dublin case (Coletta et al., 2019). It has lacked a coherent implementation plan, and only managed to agree to a few pilot projects. The case study evaluation identified specific trends and characteristics of the city that mitigate against creating a smart city in Port of Spain. These trends have not been reversed and the eight-year timetable suggested by the Action Plan has not been met. In effect, the Port of Spain case mirrors the assessment of Dublin, Ireland, which, according to Coletta et al. (2019), will continue as an accidental, rather than definitively planned smart city.

\section{Weaknesses of Smart City Model \\ Port of Spain's smart city action was reported in the media as a program of the public sector implementing an ICT platform for securing greater efficiency in the delivery of public services. This approach carries the risk that additional technological devices applied in cities will increase energy use and complexity of life, leave older citizens behind, heighten security risks, and face the profit motivation charge (Glasmeier \& Nebiolo, 2016; Allam \& Glasmeier, 2018).}

Table 2. Case Study Evaluation of Port of Spain

\begin{tabular}{ll}
\hline $\begin{array}{l}\text { Evaluation } \\
\text { characteristics }\end{array}$ & \multicolumn{1}{c}{ Results } \\
\hline Economic context & $\begin{array}{l}\text { The economy of the city and country was affected by the decline } \\
\text { in commodity prices and production of oil and gas } \\
\text { Population of the city is decreasing because of a lack of } \\
\text { affordable housing inside the city, while such housing is } \\
\text { available outside the city } \\
\text { The city is the main financial center and provides the bulk of the } \\
\text { country's administrative capacities }\end{array}$ \\
Functions & $\begin{array}{l}\text { The urbanization pattern renders the city vulnerable to natural } \\
\text { disasters and income inequality } \\
\text { The City Corporation is limited by its governing legislation, and } \\
\text { its dependence on central government resources. }\end{array}$ \\
\hline
\end{tabular}




\section{What are the Challenges of Building a Smart City?}

\section{Haven Allahar}

A smart city model for Port of Spain was conceptualized that sought to integrate smart urban solutions to enhance connectivity, transfer of e-government services, more energy efficient utilities, improved road and traffic management, and effective safety and security initiatives (Thorne-Mora, 2018). The launch of Wi-Fi connectivity and retrofitting of LED lights in public squares and spaces was a supporting initiative spearheaded by the national electricity and telephone companies (Loop News, 2020). However, city government actions suffered from implementation deficiencies, lack of dedicated resources, a concentration on traffic congestion-related initiatives, excluding traffic management and service development, as emphasized by Pulkkinen et al. (2019), and a lack of coordinated approaches. This led to a detriment of significant progress in attaining a higher level of city smartness.

These weaknesses reflect the flaws also recognized in the Dublin case (Coletta et al., 2019), the Aarhus, Denmark case (Snow et al., 2016), and some of the examples from Latin America (Jileta, 2016). This shows a need to balance the city core with its peripheral areas, which often are not accorded priority (de Falco et al., 2019).

\section{ICT Development Proposals}

A guide to the social and economic future of Port of Spain was produced that deals with implications for developing a smart city (The Roadmap Recovery Committee, 2020). The recommendations are as follows:

1. Accelerate the building of digital government

2. Introduce a digitization model that collaboratively delivers e-services, social support, and a data-driven decision-making environment

3. Create an e-identity for each citizen and permanent resident that enables them access to government services and digital commerce transactions, and addresses the digital divide between old and young, urban and rural, and rich and poor users

4. Develop an open-source data platform to stimulate economic activities

5. Implement e-payments for all city payment accounts

6. Provide incentives that support a technologicallyoriented, innovation, and entrepreneurial culture

7. Institute an e-money (smart currency) system and a FinTech innovation hub, where company representatives delegate infrastructure management to the cloud to focus on business development

8. Execute a strategic public education campaign about smarter cities

9. Adopt legislation to enable digital transformation together with developing cybersecurity safeguards.

The implementation of these basic initiatives will place Port of Spain, or any other city, in a position to advance its pursuit as a smart city with long-term goals. Nevertheless, these initiatives will require the appointment of a full-time, dedicated multidisciplinary team to undertake the critical development steps outlined above, which has not yet proven to be part of the available resources in the case of Port of Spain.

\section{Findings and Discussion}

Building a smart city appears to require basic adherence to a systematic process. This process involving selecting a competent leader and supporting team, completing an extensive diagnostic of the city's specific technology, human resources and institutional capacities, financial assets, limitations, and challenges, and especially building a coherent collaborative and engaging system among all stakeholders (Bouskela, et al., 2016).

Further, smart city builders can benefit from the following findings:

a) Idea champions and leaders should have expertise in digital technologies

b) Broad stakeholder involvement is vital; understanding the political, administrative, and cultural characteristics

c) Experiment with ideas and projects but focus on those attractive to citizens and firms

d) Leverage own and accessible resources

e) Create a platform private firms can use to develop new products and apps

f) Establish a research park where small firms can network and collaborate

g) Sustain a "collaborative community" (Snow et al., 2016).

Many constraints can restrict the development of smart cities. The relevant case of Dublin, Ireland (Coletta et al., 2019) provides sound insights into the flaws to avoid:

1. A piecemeal approach and lack of guiding strategy

2. Poor coordinated thinking among stakeholders

3. Weak governance structures and leadership

4. Lack of a formal process for local authorities to engage with stakeholders to advance collaboration

5 . Lack of resources and capacity of staff

6. Imbalance in capacity and lack of cooperation among local authorities 


\section{What are the Challenges of Building a Smart City?}

\section{Haven Allahar}

7. Working practices that impede proper procurement, experimentation, and operations

8. Implementation impacted negatively by political and regulatory barriers.

Building smart cities must rest upon a suitable policy framework that supports:

a) Framing policies within an urban development strategy

b) Evaluating success by considering policy integration, clear branding strategy, and a demand-driven approach

c) Building on existing capabilities and strengths

d) Focusing on core areas of intervention

e) Coordinating departments of the developing smart city

f) Involving a broad representation of stakeholders

g) Combining digital improvements with physical and institutional changes

h) Implementing small-scale integrated projects for early success (Caragliu \& Del Bo, 2016).

The empirical assessment of Port of Spain as an aspiring smart city, revealed that some of the key elements were being put in place, but that dedicated, focused leadership was lacking, no clear master plan was in evidence, ICT was applied in an uncoordinated manner, and greater efforts were needed to cement collaboration among a broad range of stakeholders. The latter especially was seen as an indispensable condition for achieving smart city objectives, because "a smart city is a collaborative community” (Snow et al., 2016).

Smart city development in Port of Spain is nevertheless still anticipated to deliver significant benefits with implications for city leaders and citizens. Some of the following are currently being anticipated there:

1. Generating integration which provides better information for decision-making

2. Optimizing the allocation of resources

3. Encouraging superior customer services

4. Improving public sector efficiency by creating common procedures and protocols

5. Capturing greater citizen participation on a collaborative basis facilitated by technological tools

6. Creating performance indicators for measuring, benchmarking

7. Enhancing public sector policy (IDB, 2016).

\section{Conclusions}

In the absence of a fixed definition of a smart city, this paper adopted a definition to focus the discussion by combining relevant aspects of available definitions in the literature. The definition here highlighted that people are at the core of smart cities, which invest in human and social capital, emphasize citizen collaboration, and incorporate ICTs geared to improving their citizens' quality of life. Despite the tendency to emphasize the role of ICT and smart technological devices in gradually creating smarter cities, the narrative supported the contention that technology should not be the main focus of smart city builders. Instead, emphasis should be placed on both first securing the right leadership and then building deep collaboration among participants in an appropriate "helix-style" collaborative arrangement, whether triple, quadruple or other similar form. In attempting to create a smart city, the paper presents several lists with guidelines that can greatly assist smart city efforts, through initiatives that identify an effective leadership team, conduct analyses of challenges, implement plans efficiently, adopt wide stakeholder collaboration, and measure results.

Port of Spain is a city that is now equipped with the supporting studies and plans needed to enable its advance upon building-block steps towards having smarter city status. However, the organizational initiatives lag behind, including, first, identifying a leader, manager, and team to spearhead the project, and then developing collaboration with stakeholders on the basis of an appropriate helix arrangement. This situation has led to the current conditions, in which many key public and utility services, support facilities, and urban mobility have suffered, while urban degradation keeps it below a minimum sustainability level. Generally, the building of Port of Spain as a smart city is progressing slowly and greater stimulation of design, planning, and implementation is needed.

Cities are becoming increasingly complex and seemingly unmanageable entities. This highlights the need for a debate on the smart city model, especially in managing a city's ICTs environment. In brief, a smart city places its residents at the center of development, incorporates ICTs into urban management, adopts coordinated thinking and strong governance, develops a collaborative implementation plan, and emphasizes competent leadership. Smart cities have an overarching 


\section{What are the Challenges of Building a Smart City?}

\section{Haven Allahar}

objective to build and develop in ways that significantly improve the quality of life of citizens. This objective is linked to the city becoming more innovative, competitive, attractive, resilient, and sustainable as years go by.

\section{References}

Allahar, H. 2015. Small Island Visitor Attractions: A Development Process Framework. SAGE Open, January-March: 1-14.

http://dx.doi.org/10.1177/215844015577113

Allahar, H. 2019. A Management Innovation Approach to Project Planning. Technology Innovation Management Review, 9(6): 4-13.

http://dx.doi.org/10.22215/timreview/1245

Allahar, H. \& Sookram, R. 2019. A University Business School as an Entrepreneurial Ecosystem Hub. Technology Innovation Management Review, 9(11): 1525.

http://dx.doi.org/10.22215/timreview/1280

Allam, Z. \& Newman, P. 2018. Redefining the Smart City: Culture, Metabolism and Governance. Smart Cities, 1 : 4-25.

http://dx.doi.org/10.3390/smartcities1010002

Beard, T. 2012. Sustainable Cities: The Case of Greater Port of Spain. In Fast Forward Planning in a Hyper Dynamic Urban Context. 48th Congress of the International Society of City and Regional Planners (ISOCARP), Perm, Russia, September10-13, 2012.

Bouskela, M., Casseb, M., Bass, S., De Luca, C. \& Facchina, M. 2016. The road towards smart cities: Migrating from traditional city management to the smart city. IDB Monograph 454, Washington DC: Inter-American Development Bank.

Available at www.iadb.org

Bibri, S.E. \& Krogstie, J. 2017. Smart sustainable cities of the future: An extensive interdisciplinary literature review. Sustainable Cities and Society, 31: 183-212.

http://dx.doi.org/10.1016/j.scs.2017.02.016

Caragliu, A. \& Del Bo, C.F. 2016. Do Smart cities invest in smarter policies? Learning from the past, planning for the future. Social Sciences Computer Review, 34(6): 657-672.

http://dx.doi.org/10.1177/0894439315610843

Carayannis, E.G., Barth, T.D. \& Campbell, D.F.J. 2012. The quintuple helix innovation model: Global warming as a challenge and driver for innovation. Journal of Innovation and Entrepreneurship, 1-12.

Cleveland, M. \& Cleveland. S. 2018. Building engaged communities -A collaborative leadership approach. Smart Cities, 1, 155-162.

http://dx.doi.org/10.3390/smartcities1010009
Colding, J., Colding, M. \& Barthel, S. 2020. The smart city model: A new panacea for urban sustainability or unmanageable complexity. Environment and Planning B: Urban Analytics and City Science, 47(1): 179-187.

http://dx.doi.org/10.1177/2399808318763164

Coletta, C., Heaphy, L. \& Kitchin, R. 2019. From the accidental to articulated smart city: The creation and work of 'Smart Dublin'. European Urban and Regional Studies, 26(4): 349-364.

http://dx.doi.org?10.1177/0969776418785214

Dasgupta, M. 2015. Exploring the relevance of case study research. Vision, 19(2): 147-160.

http://dx.doi.org/10.1177/0972262915575661

Datta, A. 2015. New urban utopias of postcolonial India: 'Entrepreneurial urbanization' in Dholera smart city, Gurjarat. Dialogues in Human Geography, 5(1): 3-22. http://dx.doi.org/10.1177/2043820614565748

de Falco, S., Angelidou, M. \& Addie, J-P. D. 2019. From the "smart city" to the "smart metropolis"? Building resilience in the urban periphery. European Urban and Regional Studies, 26(2): 205-223.

Etzkowitz, H. \& Leydesdorff, L. 2000. The dynamics of innovation: From national systems and "Mode 2" to a triple helix of university-industry-government relations. Research Policy, 29, 109-123.

Fletcher, K-M. 2020. City marks 106 years with low-key ceremony. Saturday Express News. http://www.trinidadexpress.com

Giffinger, R., Fertner, C., Kramar, H., Kalasek, R., Meijers, E. \& Pichler-Milanović, N. 2007. Smart cities: ranking of European medium-sized cities. Centre of Regional Science, University of Technology, Vienna.

http://www.smart-cities-

s.eu/download/smart_cities_final_report.pdf

Glasmeier, A.K. \& Nebiolo, M. 2016. Thinking about smart cities: The travels of a policy idea that promises a great deal, but so far has delivered modest results. Sustainability, 8(1122): 1-11.

http://dx.doi.org/10.3390/su8111122

Hayat, P. 2016. Smart cities: A global perspective. India Quarterly, 72(2): 177-191. http://dx.doi.org/10.1177/0974928416637930

Ho, E. 2017. Smart subjects for a smart nation? Governing (smart) mentalities in Singapore. Urban Studies, 54(13): 3101-3118. http://dx.doi.org/10.1177/0042098016664305

Inter-American Development Bank (IDB). 2012. Sustainable Port of Spain, Trinidad and Tobago: Action Plan. Washington, DC: IDB.

Inter-American Development Bank. 2016. Caribbean Case Study Evaluation of IDB's Emerging and Sustainable Cities Initiative. Office of Evaluation and Oversight OVE, Confidential Paper RE-501-1, Washington, DC: IDB.

www.iadb.org 


\section{What are the Challenges of Building a Smart City?}

\section{Haven Allahar}

Jileta, I. 2016. Performance and competitiveness of Latin American cities: The physical capital case. Theoretical and Empirical Researches in Urban Management, 11(3): 5-17.

Jussila, J., Kukkamaki, J., Mäntyneva, M. \& Heinisuo, J. 2019. Open data and open source enabling smart city development: A case study in Häme region. Technology Innovation Management Review, 9(9): 2533.

http:/ /dx.doi.org/10.22215/timreview/ 1266

Kola-Bezka, M., Czupich, M. \& Ignasiak-Szulc, A. 2016. Smart cities in Central and Eastern Europe: Viable future or unfulfilled dream. Journal of International Studies, 9(1): 76-87.

http://dx.doi.org/10.14254/2071-8330.2016/9-1/6

Kong, L. \& Woods, O. 2018. The ideological alignment of smart urbanism in Singapore: Critical reflections on a political paradox. Urban Studies, 55(4): 679-701. http://dx.doi.org/10.1177/0042098017746528

Leydesdorff, L. 2012. The triple helix, quadruple helix ..., and an n-tuple of helices: Explanatory models for analyzing the knowledge-based economy. Journal of the Knowledge Economy, 3: 25-35.

http://dx.doi.org/10.1007/s13132-011-0049-4

Loop News. 2020. Public Wi Fi and LED lights for Port of Spain. January 31.

www.looptt.com/category/looptt-t-t-news

Markkula, M. \& Kune, H. 2015. Making smart regions smarter: Smart specialization and the role of universities in regional innovation ecosystems. Technology Innovation Management Review, 5(10): 715.

http:/ / timreview.ca/article932

McAdam, M. \& Debackere, K. 2018. Beyond Triple Helix Toward Quadruple Helix Models in Regional Innovation Systems: Implications for Theory and Practice. R\&D Management, 48(1): 3-6.

Meijer, A. \& Bolivar, M.P.R. 2016. Governing the Smart city: A review of the literature on smart urban governance. International Review of Administrative Sciences, 82(2): 392-408. http://dx.doi.org/10.1177/0020852314564308

Meijer, A.J., Gil-Garcia, J.R. \& Bolivar, M.P.R. 2016. Smart city Research: Contextual condition, governance models, and public value assessment. Social Sciences Computer Review, 34(6): 647-656.

http://dx.doi.org/10.1177/0894439315618890

Metatech Publications. 2020. Smart city Malta. The Smart City Journal.

www.thesmartcityjournal.com/en/articles/732smartcity-malta

Min, K., Yoon, M., \& Furuya, K. 2019. A comparison of a smart city's trends in urban planning before and after 2016 through keyword network analysis. Sustainability, 11(3155): 1-25. http://dx.doi.org/10.3390/su11113155
Offenhuber, D. 2019. The platform and the bricoleur- Improvisation and smart city initiatives in Indonesia. EPB: Urban Analytics and City Science, 46(8): 1565-1580.

http://dx.doi.org/10.1177/2399808319865749

Pereira, G.V., Parycek, P., Falco, E. \& Kleinhans, R. 2018. Smart governance in the context of smart cities: A literature review. Information Polity, 23(2): 143-162. https://dx.doi.org/10.3233/IP-170067

Pulkkinen, J., Jussila, J., Partanen, A., Trotskii, I. \& Laiho, A. 2019. Smart mobility: Services, platforms and ecosystems. Technology Innovation Management Review, 9(9): 15-24.

http://dx.doi.org/10.22215/timreview/1265

Ruohomaa, H., Salminen, V \& Kunttu, I. 2019. Towards a smart city concept in small cities. Technology Innovation Management Review, 9(9): 5-14. http://dx.doi.org/10.22213/timreview/1264

Sahadut, M.R., Bundhoo, M.H. \& Catherine, P.C. 2015. The establishment of smart cities in Mauritius: Requirements, challenges and opportunities. Proceedings of the Second International Conference on Data Mining, Internet Computing, and Big Data, Reduit, Mauritius: 69-83.

Sánchez-Corcuera, R., Nuñez-Marcos, A., SesmaSolance, J., Bilbao-Jayo, A., Mulero, R., Zulaika, U., Azkune, G. \& Almeida, A. 2019. Smart cities survey: Technologies, application domains and challenges for the cities of the future. International Journal of Distributed Sensor Networks, 15(6): 1-36.

http:///dx.doi.org/10.14780771'16671177/1550147719 853984

Schipper, R.P.J.R. \& Silvius, A.J.G. 2018. Characteristics of small sustainable city development: Implications for project management. Smart Cities, 1: 75-97. http://dx.doi.org/10.3390/smartcities1010005

Serrano, W. 2018. Digital systems in smart city and infrastructure: Digital as a service. Smart Cities, 1: 134154.

http://10.3390/smartcities1010008

Snow, C.C., Håkonsson, D.D. \& Obel, B 2016. A smart city is a collaborative community: Lessons from smart Aarhus. California Management Review, 59(1): 92-108. http://dx.doi.org/10.1177/0008125616683954

Siggelkow, N. 2007. Persuasion with case studies. Academy of Management Journal, 50(1): 20-24.

The Roadmap to Recovery Committee. 2020. Roadmap for Trinidad and Tobago post Covid-19 pandemic. Port of Spain: Government of Trinidad and Tobago.

Thompson, E.M. 2016. What makes a city smart? International Journal of Architectural Computing, 14(4): 358-371.

http://dx.doi.org/10.1177/147807716670744

Thorne-Mora, S. 2018. Smart technologies transforming the way we live. Ministry of Housing and Urban Development, Media Release, July 9, 2018, Port of Spain, Trinidad and Tobago. 


\section{What are the Challenges of Building a Smart City?}

\section{Haven Allahar}

United Nations Habitat. 2012. Port of Spain urban profile. United Nations Human Settlements Programme.

http://www.unhabitat.org

United Nations. 2018. 68\% of the world population projected to live in urban areas by 2050. Department of Economic and Social Affairs.

https://www.un.org/development/desa/en/

van Waart, P., Mulder, I. \& de Bont, C. 2016. A participatory approach for envisioning a smart city. Social Sciences Computer Review, 34(6): 708-723. http://dx.doi.org/10.11770894393156111099

Veselitskaya, N., Karasev, O. \& Beloshitskiy, A. 2019. Drivers and barriers for smart cities development. Theoretical and Empirical Researches in Urban Management, 14(1): 85-110.

Yin, R.K. 2003. Case study research: Design and methods (3rd ed.). Thousand Oaks, California: Sage Publications.

\begin{abstract}
About the Authors
Haven Allahar has served for 25 years as an adjunct lecturer in entrepreneurship and innovation, and a coach of MBA teams' capstone projects at the Arthur Lok Jack Global School of Business of the University of the West Indies, Trinidad and Tobago. Haven has a wide academic and specialized training background in Economics (B.Sc. - Jamaica), Entrepreneurship and Management (M.A. and DBA - USA); Industrial Project Planning, Financing, and Management (UK and Poland). Haven served for over 40 years in senior management and CEO positions in companies involved in developing and managing an energybased industrial park, SME development, urban development, and project planning and management. Haven, along with two partners, owned and operated a consulting firm for 15 years that provided project planning, design, and management services to a variety of clients in Trinidad and Tobago and the Caribbean. Haven's research interests are in broad areas of business, management, and economic development issues. His publications are available at Academia.edu and ResearchGate.
\end{abstract}

Citation: Allahar, H. 2020. What are the Challenges of Building a Smart City? Technology Innovation Management Review, 10(9): 38-48. http://doi.org/10.22215/timreview/1388

\section{(cc) BY}

Keywords: Smart cities concept, smart city initiatives, ICT and smart cities, building smart cities, smart city case studies. 